\title{
OPTIMALISASI MEDIA SOSIAL TERHADAP PEMASARAN DI USAHA MIKRO KECIL MENENGAH
}

\author{
Dwi Ageng Setyawan \\ Nurul Ila Sari \\ Iza Auhaina Kuswindari \\ Diana Etika Sari \\ Izza Sakhara \\ Nanik Kustiningsih \\ Jurusan Akuntansi, Sekolah Tinggi Ilmu Ekonomi Mahardhika \\ e-mail: dwiageng24@gmail.com
}

\begin{abstract}
The purpose of this mentoring to increase sales turnover in SMES Teh Rina catering. Social media utilization as an effective marketing strategy for all businesses, ranging from food, clothing, banking business and other services. Social media utilization is based on developing the rapid existence of smart gadgets that use is very commonplace for anyone. Social Media marketing strategy is very familiar to cyber users, especially the contemporary community. Many social media uses are intended as product promotion. It is one of the cultures of modern society that is more practical in accessing everything through its respective door gadgets. Social Media is a real example of making marketing more attractive, getting better and more practical. With digital smart gadgets and Internet data packages, people are already able to access and also market their wares there. Some platforms are very well used because it relies on images as the main attraction, it also comes with the facility of writing comments and also a short direct message making the favorite social media among the corpse. Catering business is also like not to lose to utilize social media, as the research is made. The catering of Teh Rina gets positive results with the existence of this social media. Discussions using social media as a tool for business development (product marketing) showed significant results.
\end{abstract}

Keywords: social, media, marketing, mentoring, SMES

\section{PENDAHULUAN}

Kreativitas dan kecerdasan membaca situasi merupakan dua hal yang bisa menghasilkan pemasukan di bidang keuangan. Terkadang tidak setiap orang bisa menyadari kesempatan yang bisa dimanfaatkan dalam kondisi tertentu. Ini bisa timbul karena suatu hal yang terdesak misalkan, pemutusan hubungan kerja, keadaan ekonomi yang memburuk, kebutuhan hidup yang meningkat serta sebab-sebab lain yang melatar belakanginya. Seseorang akan terusik dengan kondisi lingkungan dalam hal ini melakukan adaptasi tentang kebutuhan yang diperlukan dengan kondisi nyata yang terjadi. Menghadapi situasi yang menyebabkan tidak nyaman dalam hal memenuhi kebutuhan hidup, masing-masing individu memiliki cara yang berbeda.

Berawal dari fenomena diatas, saat ini banyak bermunculan bisnis kecil yang dijalankan dari rumah-rumah. Bisnis kecil ini berkecimpung dalam kategori makanan, minuman, fashion, sepatu, sandal dan kebutuhan sehari-hari lainnya.
Penyebutan untuk mereka adalah home industry atau lebih tepat dengan istilah Usaha' Kecil Mikro Menengah (UMKM). Keberadaan UMKM bisa dimulai dengan sebuah keahlian khusus dengan bidang yang dikuasainya atau berawal dari pertemanan di komunitas tertentu, bermula mencoba bisnis tertentu karena terdesak situasi sehingga harus memulai dari awal. Jatuh bangun mungkin mereka alami, itu semua berjalan dengan alami. Keberhasilan memang memerlukan usaha yang keras dan usaha pantang menyerah.

Dari semua UMKM yang ada sebagian besar memiliki kesamaan dalam hal promosi produk. Mereka mayoritas menggunakan sosial media untuk mempromosikan produk kepada calon pembeli. Ini dibutuhkan pengetahuan mendalam tentang teknologi kekinian. Peluang peningkatan volume penjualan produk yang dipasarkan melalui sosial media memang cukup menjanjikan. Apalagi dengan melihat penggunaan smartphone yang sudah hampir mencakup semua kalangan, maka 
p-ISSN 1693-1378

e-ISSN 2598-9952

mempermudah promosi yang dilakukan pemilik UMKM.

Munculnya pengusaha-pengusaha baru dipicu oleh perkembangan dunia bisnis dalam bidang khususnya kuliner. Berhubungan dengan kebutuhan sehari-hari manusia, maka bisnis di bidang kuliner adalah bisnis yang menjanjikan. Banyaknya makanan unik yang muncul, trend wisata kuliner, serta kuliner yang dijadikan sebagai gaya hidup masyarakat, adalah bukti bahwa perkembangan bisnis kuliner sangat signifikan. Banyaknya warung makan, kedai kopi dan rumah makan baru menjadi salah satu penyebab pertumbuhan bisnis kuliner berkembang pesat.

Katering Teh Rina merupakan salah satu bisnis kuliner yang berkembang di kota Surabaya bergerak dibidang jasa penyedia makanan sehat dengan bahan alami bercitarasa makanan khas Indonesia. Produk makanan hasil olahan katering ini sudah terbukti kelezatannya dan cocok dengan selera orang umumnya. Selama ini pesanan datang hanya dari kenalan di lingkungan tempat tinggal atau teman kerja suami pemilik katering. Sehingga dalam upaya pemasaran, katering Teh Rina mengalami berbagai hambatan.

Kondisi tersebut dapat dilihat pada Gambar 1, berdasarkan grafik ini terlihat bahwa omzet katering tidak stabil dan cenderung menurun dalam enam bulan terakhir. Di bulan april sebeasar 85 juta, kemudian turun menjadi 80 juta dibulan selanjutnya. Sebetulnya terjadi peningkatan di bulan juni di angka 95 juta, akan tetapi berkurang menjadi 85 juta di bulan berikutnya. Sedikit kenaikan di bulan agustus diangka 90 juta kemudian menurun tajam di bulan September dia angka 80 juta.

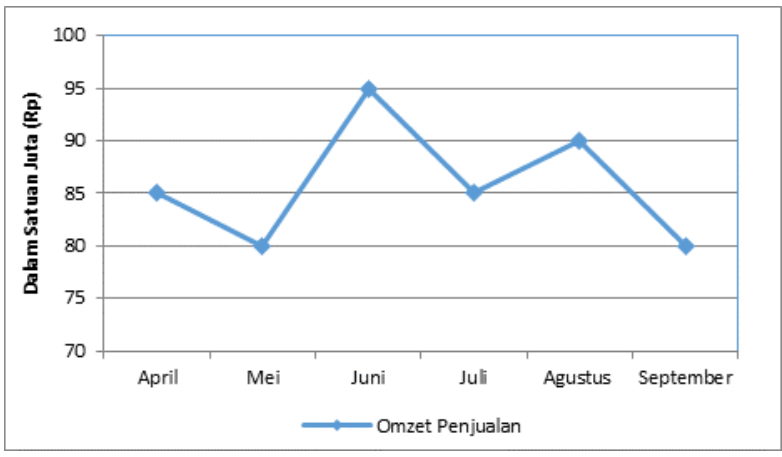

Gambar 1

Grafik Omzet Katering

Sumber: laporan keuangan katering
Optimalisasi Media Sosial Terhadap... (Dwi Ageng S., Nurul Ila Sari, Iza Auhania K. dkk)

Kendala yang dihadapi katering Teh Rina lainnya adalah kurangnya informasi yang didapatkan konsumen tentang katering Teh Rina. Faktor penting yang bisa merubah pikiran konsumen dalam mengambil keputusan tentang pembelian adalah informasi tentang produk. Pemahaman konsumen terhadap suatu produk dipengaruhi oleh informasi yang positif ataupun negatif dari konsumen. Selama proses pembuatan keputusan, saat menerjemahkan informasi yang bisa ditemukan di lingkungan mungkin pengetahuan dapat diperoleh (Nandan L dan J. Supranto., 2011).

Ciri-ciri yang tersedia pada merek-merek dipelajari oleh para konsumen. Sebuah proses dimana konsumen mengenal masalahnya, mencari informasi mengenai produk atau merk tertentu dan mengevaluasi secara baik masing - masing alternatif tersebut dapat memecahkan masalahnya, yang kemudian mengarah kepada keputusan pembelian (Tjiptono, 2012). Kesimpulan pernyataan - pernyataan di atas yaitu evaluasi yang akan dilakukan konsumen terhadap beberapa pilihan yang tersedia dan konsumen memilih produk yang dapat memberikan kepuasan serta manfaat. Informasi lainnya yang akan dipelajari konsumen adalah informasi produk yang akan dibeli. Masyarakat di era global mulai menggunakan media internet sebagai alat untuk mencari berbagai informasi. Perkembangan teknologi internet mempengaruhi cara manusia dalam berkomunikasi. Dimana pun dan kapanpun, seseorang bisa berkomunikasi tanpa ada batasan negara. Manusia berada serta dapat berbagi segala macam informasi tanpa terhambat ruang dan waktu. Hermawan (2012) menyatakan melalui jaringan internet, dimanapun di dunia ini bisa terkoneksi dengan internet, segala bentuk hambatan geogafis terhapuskan. Selain mengubah kebiasaan manusia dalam hal berkomunikasi, efek pembeda yang diberikan internet adalah dalam hal upaya pemasaran.

Pemasaran internet (e-marketing) yaitu pemasaran kepada orang banyak secara seketika dan secara massal dalam waktu tertentu menggunakan teknologi internet (Wikipedia, 2016). Dari grafik pengguna internet (Gambar 2) pemakai internet di Indonesia pada awal tahun 2019 mencapai 150,0 juta pengguna dari jumlah penduduk sebanyak 268,2 juta. Saat ini ada sekitar 150,0 juta pengguna aktif media sosial serta pengguna sosial media mobile sekitar 130,0 juta di Indonesia (wearesocial.com,2019). 


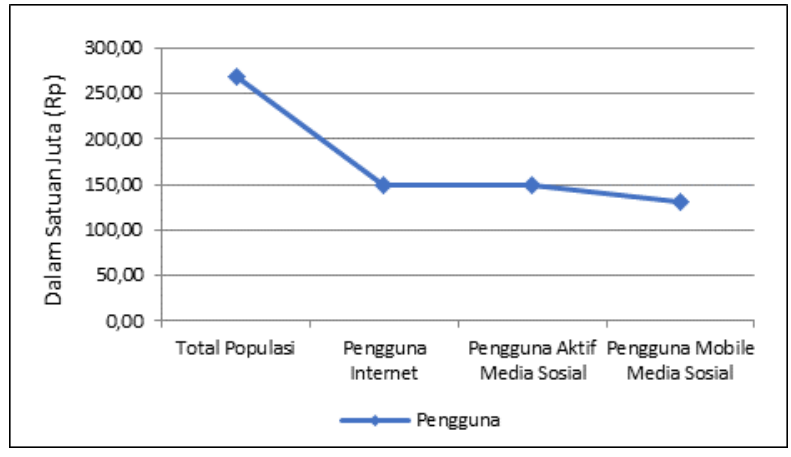

Gambar 2

Grafik Pengguna Internet di Indonesia

Sumber: wearesocial.com

Masyarakat yang memakai internet dan sosial media menjadikan para pelaku bisnis mempunyai peluang besar dalam memperkenalkan produkproduknya. Red - hot digunakan Hermawan dan Hayden di dalam Hermawan (2012) bahwa pemasaran via internet memiliki peluang yang besar. Memasarkan produk memakai internet dapat lebih membantu, karena internet memungkinkan respon yang lebih cepat, lebih efektif dalam proses pemasaran, dan biaya yang lebih hemat. Dengan biaya yang murah dan penyebaran informasi yang cepat diharapkan dapat meningkatkan penjualan sehingga katering Teh Rina dapat mencapai omzet yang sesuai target.

Melalui media sosial, katering Teh Rina juga dapat berkomunikasi dengan konsumen secara interaktif juga dapat mengetahui respon dari konsumen terhadap produk yang katering Teh Rina pasarkan melalui komentar yang dipost. Mempererat hubungan baik kepada konsumen dengan cara komunikasi yang baik. Hal itu secara tidak langsung dapat membuat konsumen merasa diperhatikan sehingga hal tersebut dapat menciptakan kepuasan bagi konsumen. Apabila konsumen mendapatkan kepuasan, maka konsumen akan secara tidak langsung memberikan kesan yang positif dan kemudian akan merekomendasikan kepada orang lain.

Begitu masifnya pengguna media sosial di Indonesia, bisa dimanfaatkan dengan sebaikbaiknya. Jika pemilik UMKM bisa membaca peluang pengguna media sosial mayoritas melalui platform apa, maka hasil maksimal bisa diperoleh. Berdasarkan pada grafik dari Gambar 3 dapat dilihat bahwa ada 6 aplikasi jejaring sosial dengan pengguna terbanyak di Indonesia di aawal 2019 adalah : Youtube (88\%), Whatsapp (83\%), Facebook (81\%), Instagram (80\%), Line (59\%),
Twitter (52\%). Data tersebut tentu saja merupakan informasi yang sangat berguna bagi pemilik UMKM untuk memaksimalkan aplikasi jejaring sosial yang menjadi media berpromosi.

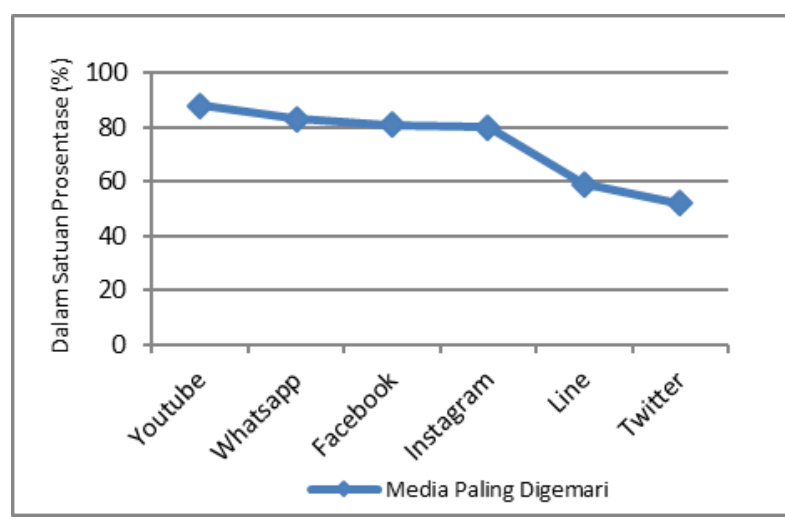

\section{Gambar 3 \\ Aplikasi Sosial Media Paling Aktif di Indonesia}

Sumber : wearesocial.com

Dengan demikian berdasarkan data yang ada pemilik usaha masih mempunyai peluang yang besar untuk memperluas pemasaran dengan menggunakan media sosial. Ini dibuktikan dengan banyaknya pengguna media sosial aktif di Indonesia serta aplikasi apa saja yang menjadi top ten di kalangan pengguna aktif yang memanfaatkannya. Maka tepat kiranya jika penelitian ini yang dalam pelaksanaannya berbentuk pendampingan kami beri judul "Optimalisasi Media Sosial Terhadap Pemasaran di UMKM Katering Teh Rina".

\section{Tinjauan Literatur \\ Marketing Digital}

Marketing digital merupakan cara pemasaran menggunakan teknologi digital. Salah satu bentuk pemasaran digital menggunakan internet dan media elektronik adalah e-marketing (internet marketing). Menurut Chadwick, Chaffey, Mayer, dan Johnston, (2006:9), Electronic Marketing atau E-Marketing merupakan teknologi komunikasi elektronik khususnya internet yang membantu proses pemasaran. Dalam mengikuti perkembangan teknologi digital dan rencana untuk menarik konsumen adalah dengan menyadari peran strategi digital marketing ke arah media internet adalah hal yang penting dan menuntun pada perpaduan antara komunikasi tradisional dan komunikasi elektronik. Menurut Chaffey (2009), dengan meningkatkan pengetahuan tentang 
konsumen seperti nilai, perilaku, tingkat loyalitas dan profil dapat mencapai retensi tersebut, selanjutnya menyatukan pelayanan online dan komunikasi yang ditargetkan sesuai kebutuhan individu masing-masing. Teori ini digunakan dalam penelitian untuk membahas bentuk strategi yang digunakan dalam perkembangan teknologi ke depan. Marketing digital memiliki peranan penting dalam strategi pemasaran terutama pada objek penelitian ini, yaitu strategi marketing yang dilakukan oleh Katering Teh Rina.

\section{Media Sosial dalam Pemasaran}

Dalam bukunya yang berjudul Social Media Marketing Evans (2012), media sosial adalah proses perpaduan dalam menyebarkan, membentuk, menghancurkan dan mengubah informasi. Sosial media dapat mengelompokkan sejumlah pengetahuan dan informasi, tetapi perlu diperhatikan secara mendalam kebenaran dari hal tersebut. Maka dari itu, sosial media berperan lebih efektif dalam tindakan bersosialisasi atau partisipasi dan mempengaruhi publik, bukan mengontrol mereka atau pun memberikan pernyataan. Partisipasi dalam sosial media dapat menyebabkan pengaruh dan tujuan bisnis serta pemasarannya dapat tercapai. (Evans, 2012:34).

Menurut Evans (2012) grafik proses pembelian klasik adalah sebagai berikut:

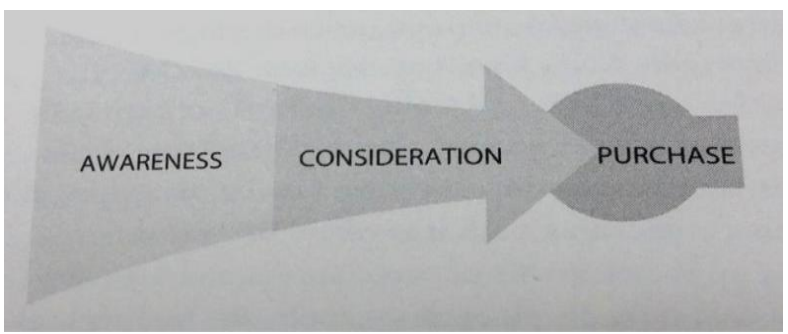

\section{Gambar 4 \\ The Classic Purchase Funnel}

Sumber: Evans, 2012

Penelitian ini apabila dikaitkan dengan teori perputaran tanggapan sosial (Evans, 2012:44), marketing yang dilakukan oleh Katering Teh Rina berbentuk media sosial. Para pembeli produk tersebut akan memberikan pendapat mereka dalam bentuk pernyataan di media sosial. Peneliti akan mengamati bagaimana perputaran proses pembelian produk dan memberikan penjelasan dalam bentuk bagan untuk menggambarkan teori tersebut.
Optimalisasi Media Sosial Terhadap... (Dwi Ageng S., Nurul Ila Sari, Iza Auhania K. dkk)

\section{Usaha Mikro Kecil dan Menengah}

Berdasarkan Usaha Kecil Menengah dan Kementrian Negara Koperasi, Badan Pusat Statistik (BPS), dan UU No. 20 Tahun 2008, yang dimaksud dengan Unit Kerja Mandiri (UKM) adalah perusahaan yang membukukan total penjualan tahunan kurang dari $\mathrm{Rp} 50$ miliar atau mempunyai modal bersih kurang dari Rp 10 miliar diluar tanah dan bangunan (Suryadi, 2014).

Menurut Buyer (2015), Juju et al (2010), dan Bajpai, Pandey, \& Shriwas (2012) bahwa media sosial adalah bentuk hubungan masyarakat (humas) yang paling transparan, menarik dan interaktif pada saat ini. Media sosial terkadang lebih dapat menarik perhatian dibanding masyarakat di dunia nyata. Fenomena ini kemudian dijadikan sebagai suatu jalan untuk menanamkan merek dibenak konsumen dengan dukungan media sosial. Pelaku Usaha Kecil dan Menengah (UKM) dapat memanfaatkan media sosial yang bersifat terbuka untuk memasarkan produknya. Media sosial seperti Facebook, Twitter dan Instagram dapat digunakan dengan cara dimulai dari dengan memajang foto-foto serta detail mengenai produknya. Penghematan biaya dapat dilakukan dengan cara ini secara efektif dan ampuh. Hal ini tentu saja menghilangkan cara lama yaitu mempromosikan barang dengan menggunakan jasa dari sales yang langsung menemui konsumen di jalan. Konsumen akan merasa lebih dekat dengan teknik pemasaran melalui media sosial karena hal ini tepat sasaran. Produk yang disukai oleh konsumen bisa langsung di respon dengan cara di klik like, share, comment di media sosial ataupun sebaliknya.

\section{Bisnis Katering}

Membuat persiapan serta menyajikan makanan lengkap dengan minuman untuk umum bisa diartikan dengan to cater, yang dalam bahasa sehari-hari disebut catering. Sedangkan Caterer adalah orang yang mempunyai keahlian untuk menyiapkan dan menyajikan makanan serta minuman tersebut. Sedangkan pengguna jasa ini bisa berasal dari daerah-daerah, instansi berupa perusahaan yang melayani kebutuhan makanan. Restoran, rumah makan, kantin di sekolah, cafécafé merupakan contoh dari industri catering. Usaha Catering adalah termasuk usaha multifaset dari industri penyajian makanan. Segmen ini termasuk didalamnya komersial, non komersial beserta militer, tiga segmen ini merupakan klasifikasi umum dari industri jasa makanan. Sedangkan kegiatan untuk merencanakan, 
mengorganisasikan, mengendalikan serta mengeksekusi bisa disebut dengan manajemen catering.

\section{Penelitian Sebelumnya}

Berdasarkan pada tinjauan pustaka yang telah diuraikan, terdapat beberapa tinjauan penelitian terdahulu yang dinilai mendekati dan dapat menjadi acuan bagi penulis terhadap penelitian ini. Beberapa penelitian yang menjadi acuan diantaranya adalah penelitian yang dilakukan oleh Kithinji (2014) yang meneliti mengenai performa penggunaan digital marketing terhadap UMKM, Dahnil et al. (2014) yang meneliti faktor-faktor apa saja yang memiliki pengaruh signifikan terhadap adopsi pemasaran melalui media sosial oleh UMKM, Suarmawan (2015) yang meng- identifikasikan faktor-faktor yang memengaruhi keberhasilan usaha pada UMKM dengan usaha kreatif di desa Bulian, Mokhtar (2015) yang dalam penelitiannya menunjukan hasil yang positif mengenai pengaruh adopsi digital marketing oleh UMKM di Malaysia, Mokhtar et al. (2016) dalam penelitiannya menunjukan bahwa faktor organisasi dan lingkungan teknologi yang berpengaruh signifikan terhadap adopsi internet oleh UMKM, kemudian penelitian yang dilakukan oleh Setiowati et al. (2015) yang menjelaskan betapa pentingnya pengetahuan dan wawasan yang dimiliki pelaku UMKM dalam adopsi internet dan menyadari manfaat yang akan didapatkan.

Tabel 1 menjelaskan lebih lanjut mengenai beberapa penelitian terdahulu yang menjadi acuan bagi penulis.

\section{Tabel 1 \\ Penelitian Terdahulu}

\begin{tabular}{|c|c|c|}
\hline Nama & Penelitian & Hasil \\
\hline $\begin{array}{l}\text { Kithinji, L.W. } \\
\text { (2014) }\end{array}$ & $\begin{array}{ll}\text { Internet Marketing and } \\
\text { Performance of Small and } \\
\text { Medium Enterprises in } \\
\text { Nairobi County }\end{array}$ & $\begin{array}{l}\text { Studi tersebut menemukan bahwa penggunaan internet } \\
\text { marketing memungkinkan perusahaan untuk } \\
\text { berkomunikasi dengan produk mereka yang memiliki } \\
\text { dampak positif pada kinerja mereka. Perusahaan dapat } \\
\text { memperbaiki hubungan pelanggan mereka melalui } \\
\text { penggunaan internet marketing serta mengiklankan } \\
\text { produk mereka dan melacak penjualan mereka } \\
\text { dengan lebih mudah. }\end{array}$ \\
\hline
\end{tabular}

Dahnil, M. I., $\quad$ Factors Influencing SMEs Marzuki, K. M., Adoption of Social Media Langgat, J., \& Marketing

Fabeil, N. F. (2014)

Suarmawan, Kadek Agus. (2015)

Mokhtar, N. F. (2015).

Mokhtar NF, Zuha RAH, M Abu SAH (2016)
Analysis Factors of Affecting the Business Success of SMEs Business (Study in Business Craft Ingka in The Village Bulian, Kubuambahan)

Internet Marketing Adoption by Small Business Enterprises in Malaysia

Applying Technology Organizationand

Environment (TOE) Model in Social Media Marketing Adoption: The Case of Small and Medium Enterprise in Kelantan, Malaysia.
Ada bukti signifikan untuk mengkategorikan pemasaran media sosial sebagai bagian dari pemasaran internet, dengan sumber daya terbatas, kesalah pahaman dan kurangnya pemahaman tentang teknologi akan berdampak buruk pada bisnis kecil.

Hasil penelitian menunjukkan bahwa terdapat 6 faktor yang memengaruhi keberhasilan usaha, yaitu komitmen, pengalaman, pembiayaan, motivasi dan kapasitas usaha. Dari faktor keenam faktor komitmen merupakan faktor yang paling dominan memengaruhi kesuksesan bisnis.

Temuan menunjukkan bahwa mengadopsi internet marketing membantu usaha kecil untuk memiliki cakupan pasar yang lebih luas, mengurangi biaya pemasaran, dan meningkatkan hubungan dengan pelanggan.

Temuan ini menunjukkan bahwa factor organisasi dan lingkungan teknologi berpengaruh signifikan terhadap adopsi pemasaran media sosial oleh UMKM di Kelantan, Malaysia. 


\begin{tabular}{lll}
\hline \multicolumn{1}{c}{ Nama } & \multicolumn{1}{c}{ Penelitian } & Hasil \\
\hline Setiowati R, & The effects of ICT adoption & Temuan ini mengandung wawasan berharga yang bisa \\
Hartoyo HKD, & on marketing capabilities and & mendidik pemilik atau pengelola UMKM tentang \\
Bustanul A, (2015) & $\begin{array}{l}\text { business performance of potensi keuntungan yang akan mereka dapatkan } \\
\text { Indonesian SMEs in the dengan menerapkan kemampuan hemat biaya adopsi } \\
\text { fashion industry }\end{array}$ & \begin{tabular}{l} 
internet untuk bisnis mereka. \\
\hline
\end{tabular}
\end{tabular}

Berdasarkan pada beberapa sumber penelitian sebelumnya yang telah dijelaskan di atas, penelitian ini mengacu pada penelitian yang dilakukan oleh Kithinji (2014), karena hampir mendekati tujuan dari penelitian ini. Kontribusi terbesar dari penelitian ini adalah, belum ada penelitian yang menggabungkan pengaruh tingkat penggunaan, jenis media internet yang digunakan, serta faktor pendidikan mengenai internet dan manfaatnya, terhadap adopsi digital marketing bagi UMKM dan pengaruhnya terhadap keberhasilan usahanya.

\section{METODE PENELITIAN}

Program pendampingan kewirausahaan ini dilaksanakan dengan menggunakan metode deskriptif dengan pendekatan kualitatif, yaitu suatu metode yang melakukan pengumpulan data, wawancara, dokumentasi serta interaksi dengan pengusaha UMKM. Menurut Suwartono (2014, p. 48), wawancara adalah cara menjaring informasi atau data baik melalui interaksi verbal atau lisan. Wawancara ini bertujuan agar dapat mengetahui permasalahan secara lebih terperinci dan terbuka. Sedangkan menurut Sugiyono (2013, p. 32), dokumentasi merupakan cara mengumpulkan data dimana memeriksa benda tertulis misalnya buku, majalah, dokumen, peraturan-peraturan dan sebagainya. Dokumen yang menjadi data pendukung adalah dokumen yang berkaitan dengan laporan keuangan, akun sosial media serta fotofoto produk katering Teh Rina.

\section{PEMBAHASAN}

Logo usaha merupakan hal yang sangat berperan penting dalam suatu usaha, pemilik Katering Teh Rina merasa logo yang saat ini dipakai kurang sesuai dengan keinginannya dan kurang mencerminkan karakteristik usahanya. Sehingga pemilik terinspirasi untuk membuat logo berbentuk siluet. Pembuatan design logo dengan tema tang sederhana dan elegan, kami lakukan secara berkala karena menyesuaikan kebutuhan. Dengan adanya logo usaha ini diharapkan bisa memberikan identitas usaha katering Teh Rina yang sebenarnya dan masyarakat bisa lebih mengenal keberadaan usaha katering tersebut.
Usaha katering Teh Rina ini memiliki omset yang lumayan banyak namun kartu nama yang dimiliki kurang menarik, sehingga kurang mencerminkan bentuk usaha yang sesungguhnya. Kartu nama yang dimiliki memakai logo yang beda dengan logo yang digunakan pada kemasan box makanan. Hal ini bias mengakibatkan para customer bingung, apakah ini usaha yang sama atau berbeda. Kami membuat desain kartu nama dengan tema kekinian. Kami menambahkan logo katering yang baru, logo halal dan PIRT. Dengan adanya kartu nama ini diharapkan memberikan kesan manarik dimata pelanggan, serta menampilkan logo usaha terbaru untuk lebih mengenalkan nama katering Teh Rina ini. Serta menampilkan logo halal dan PIRT guna untuk menambah kepercayaan pelanggan terhadap produk-produk yang dijual.

Dengan usaha katering yang semakin dikenal dimasyarakat luas nampaknya brosur yang dimiliki katering Teh Rina ini sangat minimalis dan kurang menarik. Brosur sangat diperlukan ketika adanya sebuah event yang sangat berpengaruh positif terhadap usaha. Pelanggan akan merekam kesan pertamanya mulai dari mencicipi makanan dan melihat brosur katering yang tersedia sehingga brosur ini memerlukan perhatian khusus untuk memikat daya beli masyarakat. Semakin menarik brosur yang ditampilkan akan memberikan kesan berkelas dimata pelanggan. Maka dengan ini kami membuatkan desain brosur yang menarik dan tentunya dengan tema yang saling berhubungan dengan karakteristik usaha dan logo yang ada. Dengan adanya perubahan ini diharapkan dapat menaikkan pendapatan usaha dan dikenal masyarakat luas.

Mengingat banyak sekali masukan dari pelanggan untuk membuat akun Grabfood maka pihak katering Teh Rina memutuskan untuk mendafatarkan menjadi mitra Grabfood. Karena akun Grabfood telah tersedia kami melakukan konfirmasi data kepada pihak Grabfood untuk memberikan kami wewenang dalam mengelola akun Grabfood katering teh rina. Sehingga kami melakukan rebranding ulang serta memberbarui berbagai macam tampilan dan juga menu. Dengan dilakukannya kemitraan terhadap Grabfood 
bertujuan untuk meningkatakan omset pada depot Teh Rina.

Dengan perbaikan beberapa aspek tersebut diharapkan meningkatkan jumlah follower katering Teh Rina. Sehingga didapatkan data sebelum pendampingan 375 followers dan setelah dilakukan pendampingan 410 followers mengalami peningkatan 35 follower.

Berikut kami sajikan beberapa perubahan yang sudah kami lakukan dalam bentuk:

Tabel 2

\section{Daftar Perubahan}

\begin{tabular}{lll}
\hline Bagian & Sebelum pendampingan & Sesudah pendampingan \\
\hline Logo usaha & & \\
& & \\
& &
\end{tabular}

Kartu nama
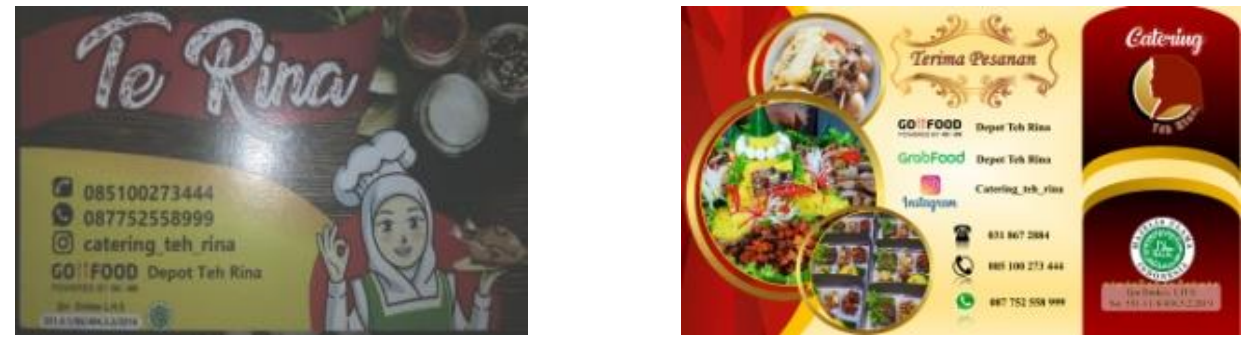

\section{Brosur}
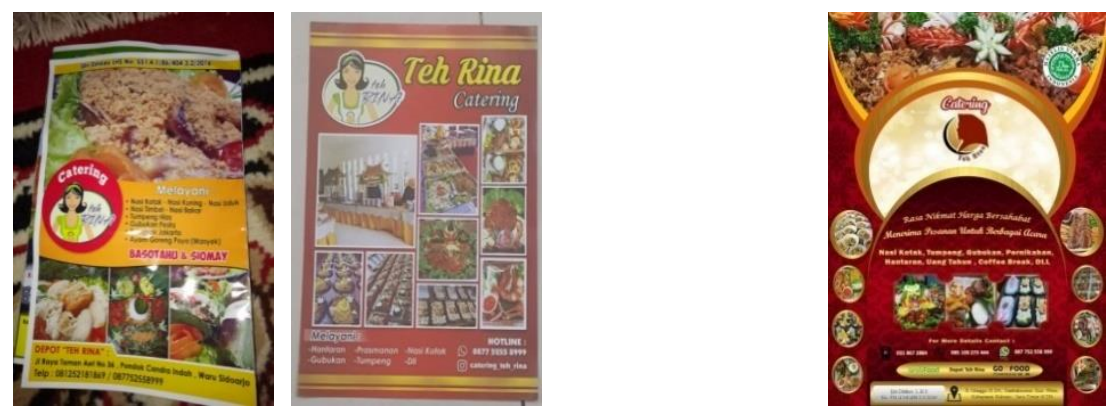

Instagram
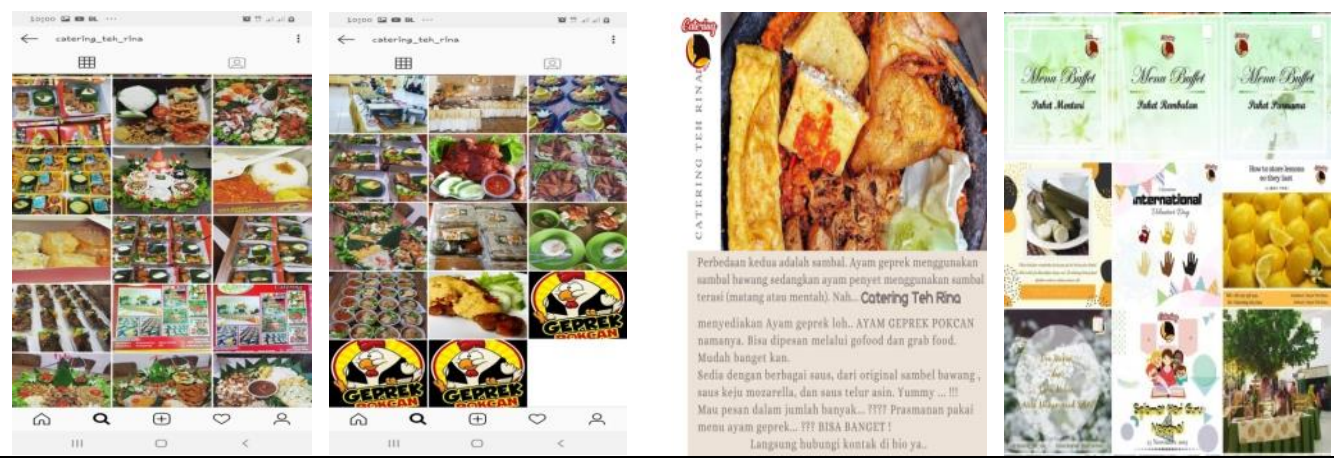


\begin{tabular}{|c|c|c|}
\hline Bagian & Sebelum pendampingan & Sesudah pendampingan \\
\hline Grab Food & 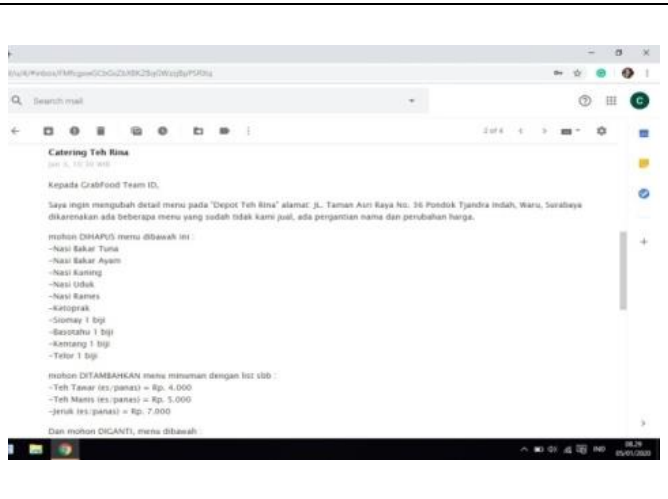 & 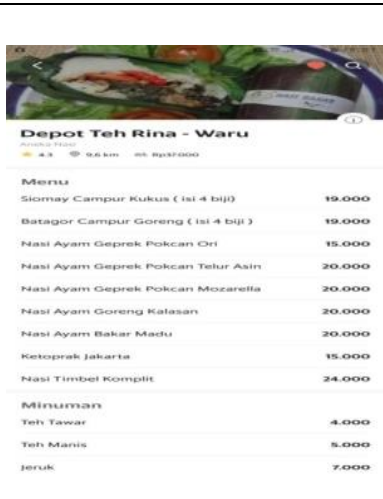 \\
\hline
\end{tabular}

Follower

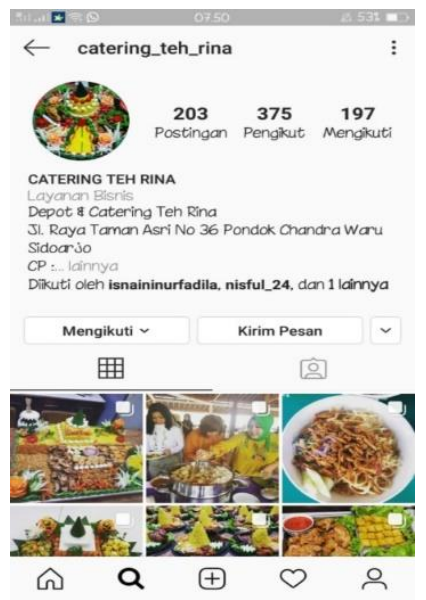

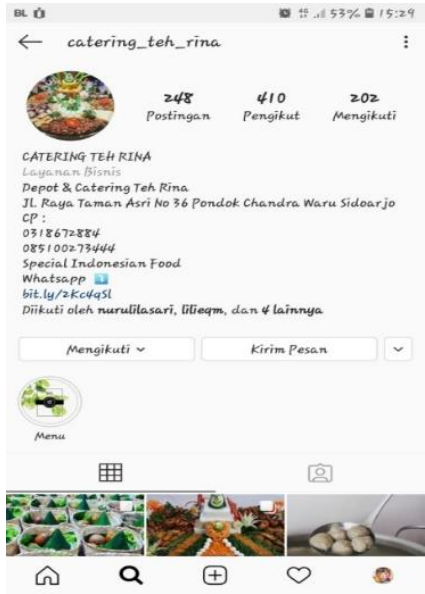

Sumber: Katering Teh Rina

Hasil pendampingan menunjukkan terjadi kenaikan jumlah pemesanan melalui sosial media yang sudah diaktifkan sebelumnya. Di awal pendampingan, hanya sekitar 375 konsumen yang sering berkomunikasi. Di akhir pendampingan terdapat penambahan sejumlah konsumen yang pernah berkomunikasi menjadi 418. Tentu saja hal tersebut menjadi salah satu petunjuk adanya jumlah kenaikan pemesanan melalui media sosial yang sudah dioptimalkan. Tjiptono (2012) menyatakan bahwa promosi ialah salah satu faktor yang menentukan keberhasilan suatu program pemasaran. Dalam hal ini katering Teh Rina menggunakan media sosial sebagai media promosi karena dirasa sangat efektif dan efisien, dikarenakan peningkatan jumlah pengguna media sosial terus bertambah setiap tahun membuat informasi yang dibagikan di media sosial dapat terus menyebar lebih luas. Katering Teh Rina juga dapat menjalin hubungan baik dengan konsumen melalui media sosial. Kotler \& Amstrong (2012). Hasil pendampingan ini mendukung adanya penelitian sebelumnya yang dilakukan oleh Nurgiyantoro (2014), keputusan pembelian konsumen dipengaruhi secara signifikan dan positif oleh promosi menggunakan sosial media.

Kegiatan pendampingan ini juga membuktikan bahwa promosi melalui media sosial juga membantu menyebarkan keberadaan katering Teh Rina di komunitas-komunitas media sosial yang ada. Bagi katering Teh Rina yang tergolong UMKM baru di Surabaya, promosi melalui sosial media merupakan cara yang sangat efektif dan efisien dalam hal penyebaran informasi. Konsumen akan mengumpulkan berbagai informasi sebelum memutuskan membeli atau mengkonsumsi suatu produk.

Konsumen juga akan membandingkan sebagian atau seluruh informasi yang mereka terima. Hal tersebut senada dengan pernyataan Tjiptono (2012), "sebuah proses dimana konsumen mengenal masalahnya, mencari informasi mengenai produk atau merk tertentu dan mengevaluasi secara baik masing-masing 
alternatif tersebut dapat memecahkan masalahnya, yang kemudian mengarah kepada keputusan pembelian". Informasi ini dipakai dalam menganalisa semua pilihan yang tersedia dalam hal pengambilan keputusan pembelian. Konsumen mendapatkan informasi mengenai katering Teh Rina melalui media sosial, selanjutnya konsumen juga cenderung akan mencari dan membandingkan informasi tersebut dengan testimoni dari konsumen lain. Maka perlu strategi yang baik dalam menggabungkan kedua faktor tersebut agar dapat meningkatkan keputusan pembelian konsumen.

\section{PENUTUP}

\section{Kesimpulan}

Berdasarkan hasil pembahasan tersebut dapat disimpulkan bahwa promosi melalui sosial media menjadi strategi pemasaran yang cukup efektif. Hal tersebut ditunjukkan dengan bertambahnya follower di akun media sosial katering Teh Rina serta banyaknya pemesanan produk melalui aplikasi media sosial. Peningkatan ini didukung dengan kemampuan pemilik UMKM dalam memperbaharui tampilan produk baik berupa kartu nama, brosur, foto maupun video agar lebih tertata dan profesional. Namun ada beberapa faktor yang mempengaruhi yaitu:

1. Faktor Penghambat:

Karakter dari pemilik UMKM katering Teh Rina kurang adaptif dan inovatif dalam melakukan digitalisasi kegiatan marketing dikarenakan terbatasnya kemampuan dalam memanfaatkan teknologi dan media sosial yang berubah dengan cepat sesuai dengan perkembangan zaman. Sehingga menyebabkan kegiatan pemasaran digital menjadi kurang optimal karena akun sosial media katering Teh Rina jarang darawat. Customer engagement di media sosial pun sangat kurang.

Terbatasnya kemampuan SDM yang dimiliki oleh UMKM katering Teh Rina dalam hal merancang desain media pemasaran produk yang lebih tertata dan profesional menyebabkan hasil dari desain pemasaran sebelum adanya pendampingan kurang menarik secara estetika.

Tidak adanya divisi bagian marketing yang secara tetap dan fokus mengelola akun media sosial. Semua masih dilakukan secara mandiri oleh pemilik UMKM. Dan kegiatan branding produk tidak dibangun secara berkelanjutan untuk meningkatkan brand awareness.

2. Faktor Pendukung
Pemilik UMKM catering Teh Rina kooperatif dan menerima dengan baik masukan dan saran perbaikan dari kelompok pendampingan. UMKM catering Teh Rina Memiliki semangat untuk memperbaiki kegiatan marketing online yang selama ini belum optimal.

\section{Saran}

Berdasarkan hasil pendampingan disarankan: (1) Kegiatan promosi melalui media sosial, katering Teh Rina harus lebih aktif, mampu memberikan inovasi-inovasi dan penyajian pesan yang lebih unik dan menarik agar konsumen dapat lebih memahami dan tertarik dengan informasi yang diposting di media sosial, sehingga dapat lebih memberikan pengaruh dalam pengambilan keputusan pembelian; (2) Katering Teh Rina diharapkan dapat menerapkan strategi khusus untuk merangsang konsumen agar memberikan testimoni atau melakukan pembicaraan yang positif dengan orang lain, misalnya dengan meningkatkan nilai produk beserta atributnya untuk menambah kepuasan konsumen. (3). Katering Teh Rina juga harus rajin memantau Customer review yang terjadi di kalangan konsumen agar dapat mengetahui kelebihan dan kekurangan produknya, sehingga katering Teh Rina dapat mengklarifikasi testimoni negatif serta mempertahankan dan meningkatkan value produk yang mendapat testimoni positif.

\section{DAFTAR PUSTAKA}

Bajpai, V., Pandey, D., and Shriwas, M. 2012. Social Media Marketing: Strategies \& Its Impact. Indianresearchjournals.com

Buyer, L 2015. 7 Buzzfeed Signs The Social Media Revolution is Just Getting Started. https://socialprchat.com/7-buzzfeed-signsthe-social-media-revolution-is-justgetting-started/

Chaffey, D., Chadwick, F. E., Johnston, K., \& Mayer, R. 2006. Internet Marketing: Strategy, Implementation and Practice (3rd ed). Financial Times/ Prentice Hall.

Chaffey, D., Chadwick, F. E., Johnston, K., \& Mayer, R. 2009. Internet Marketing: Strategy, Implementation and Practice (4th edition). Pearson Education: Prentice Hal.

Dahnil, M. I., Marzuki, K. M., Langgat, J., \& Fabeil, N. F. 2014. Factors Influencing SMEs Adoption of Social Media 
p-ISSN 1693-1378

e-ISSN 2598-9952

Marketing. Procedia - Social and Behavioral Sciences, 148, pp. 119-126.

Evans, Dave. 2012. Social Media Marketing An Hour a Day. Indiana: John Willey \& Sons, Inc.

Hermawan, Agus. 2012. Komunikasi Pemasaran. Jakarta. Erlangga

https://id.wikipedia.org/wiki/Pemasaran_Interne $t$

https://andi.link/hootsuite-we-are-socialindonesian-digital-report-2019/

Juju, Dominikus, Sulianta. 2010. Branding Promotion with Social Network. Jakarta: Elex Media.

Kithinji, L.W. 2014. Internet Marketing and Performance of Small and Medium Enterprises In Nairobi County. Doctoral dissertation at the University of Nairobi: Published.

Kotler, Philip dan Amstrong, Gary. 2001. Prinsip-prinsip Pemasaran, Jilid 1 dan 2, Edisi 8. Jakarta. Erlangga.

Kotler, Philip dan Amstrong, Gary. 2012. Prinsip-Prinsip Pemasaran, Edisi 13, Jilid 2. Jakarta. Erlangga.

Kotler dan Keller. 2007. Manajemen Pemasaran, Jilid 1, Edisi 12. Jakarta.

Kotler dan Keller. 2009. Manajemen Pemasaran, Jilid I, Edisi 13. Jakarta. Erlangga

Mokhtar, N. F. 2015. Internet Marketing Adoption by Small Business Enterprises in Malaysia. International Journal of Business and Social Science. Vol. 6 (1). Pp: 59-65

Mokhtar NF, Zuha RAH, M Abu SAH. 2016. Applying Technology Organization and Environment (TOE) Model in Social Media Marketing Adoption: The Case of Small and Medium Enterprise in Kelantan, Malaysia. The Social Science. 11(21). 5139-5144.

Nurgiyantoro, Singgih. 2014. Pengaruh Strategi Promosi Melalui Social Media Terhadap Keputusan Pembelian Garskin Yang Dimediasi Word Of Mouth Marketing (Studi Pada Konsumen Produk Garskin Merek Sayhello Di Kota Yogyakarta). Yogyakarta. Universitas Negeri Yogyakarta

Setiowati R, Hartoyo HKD, Bustanul A. 2015. Understanding ICT Adoption Determinants among Indonesian SMEs in Fashion Subsector. International
Optimalisasi Media Sosial Terhadap... (Dwi Ageng S., Nurul Ila Sari, Iza Auhania K. dkk)

Research Journal of Business Studies. $8(01)$.

Supranto, dan Limakrisna, Nandan. 2011. Perilaku Konsumen dan Strategi Pemasaran, Edisi Kedua. Jakarta. Mitra Wacana Media.

Suwartono. 2014. Dasar-dasar Metodologi Penelitian. Yogyakarta: Andi.

Sugiyono. 2013. Metodelogi Penelitian Kuantitatif, Kualitatif Dan $R \& D$. (Bandung: ALFABETA)

Suarmawan, Kadek Agus. 2015. Analisis Faktor-Faktor Yang Mempengaruhi Keberhasilan Usaha Mikro dan Kecil (Studi Pada Usaha Kerajinan Ingkadi Desa Bulian, Kec. Kubutambahan). Jurnal Jurusan Pendidikan Ekonomi (JJPE). Vol 5 No. 1, h. 1-10.

Tjiptono, Fandy. 2012. Strategi Pemasaran, ed. 3. Yogyakarta, Andi. 